NOVO CONSTITUCIONALISMO LATINO-AMERICANO: UM CONVITE A REFLEXÕES ACERCA DOS LIMITES E ALTERNATIVAS AO DIREITO

\section{Giulia Parola}

Professora Permanente do Programa de Pós-

Graduação em Direito

Constitucional da

Universidade Federal

Fluminense, Niterói, Rio de Janeiro, Brasil. Doutora em Direito pela Université Paris V René Descartes, França. giuliaparola.law@gmail. com

\section{Loyuá Ribeiro} Fernandes Moreira da Costa

Mestre em Direito Constitucional pela Universidade Federal Fluminense, Niterói, Rio de Janeiro, Brasil.

Irfmcosta@gmail.com

Recebido: março 13, 2019

Aceito: abril 15, 2019

\section{New Latin-American Constitutionalism: An Invitation to Reflections about the Limits And Alternatives to Law}

RESUMO

A história do direito demonstra a estreita relação do Direito com a dominação de povos subalternizados e a legitimação de atos opressores, instituídos em benefício de interesses econômicos. Diante disso, a busca por um direito descolonial mostrase urgente. Para tanto, são analisadas as origens epistemológicas do direito, do constitucionalismo, dos direitos humanos e da dignidade humana, indagando se o Novo Constitucionalismo Latino-Americano seria um passo rumo à descolonização do direito. Isso porque este movimento ainda contempla um paradigma que vai de encontro às premissas dos sistemas constitucionais tradicionalmente adotados. O Novo Constitucionalismo Latino-Americano se caracteriza por constituições que inserem epistemologias indígenas em seus textos, aportando um conceito de viver bem mais amplo que o do liberalismo. As epistemologias do Sul, ao serem constitucionalmente introduzidas, exibem potencial para lidar com os dilemas da sociedade global. A urgência de se interrogar sobre um Direito pautado nas epistemologias do Sul advém da inquietação quanto às promessas não cumpridas da modernidade, que convocam o Direito a acolher estas epistemologias como seu fundamento.

Palavras-chave: Novo Constitucionalismo Latino Americano; Epistemologias do Sul; Constituição da Bolívia; Constituição do Equador. 


\begin{abstract}
Legal history established a strong link between Law, subaltern's domination, and the legitimation of oppressive acts to the benefit of economic interests. Taking this into account, the need to decolonize Law is urgent. For that reason, we intend to analyze the epistemological origins of law, constitutionalism, human rights and human dignity, questioning whether the New Latin American Constitutionalism is a step towards to the decolonization of Law. The motivation that lies behind that question is the convergence of New Latin American Constitutionalism with the premises held by traditional constitutional systems. Latin American constitutionalism marks itself by inserting indigenous epistemologies into constitutional texts and bearing a concept of good living that surpass the liberal conception. The constitutionalization of Southern epistemologies has also shown potential in dealing with global society dilemmas. The urgency to consider a legal system based on the epistemologies of the South derives from the unfulfilled promises of modernity, which requires Law itself to account for these alternatives as its foundation.
\end{abstract}

Keywords: New Latin American Constitutionalism; South Epistemologies; Constitution of Bolivia; Constitution of Ecuador.

\title{
INTRODUÇÃO
}

O estudo objetiva demonstrar as incongruências do fenômeno jurídico, ao analisar os desdobramentos e consequências do pensamento Ocidental, constatando-o como uma esfera retórica incapaz de possibilitar novos horizontes. Como pano de fundo estão os dilemas da modernidade que evidenciam a necessidade de reavaliarmos elementos que subsidiaram a consolidação do projeto de vida moderno. A investigação ora proposta objetiva analisar, precipuamente de forma descritiva, as possíveis causas deste fenômeno - a ciência jurídica, o constitucionalismo, a dignidade humana e os direitos humanos - derivadas do paradigma da modernidade, concebidas sob uma racionalidade individualista, que se depara com temáticas complexas e multifacetadas. Nesse sentido, questiona-se se o pensamento descolonial poderia ofertar críticas e um outro olhar sobre os possíveis alcances do direito.

A hipótese central desse estudo recai sobre o pensamento descolonial, com relação à sua capacidade de dar autonomia ao indivíduo para compreender os contextos e os processos histórico-sociais em 
As reflexões propostas se justificam ante a necessidade do papel do jurista e da pesquisa científica. Isso porque as pesquisas jurídicas não podem ignorar as dinâmicas de poder contidas na construção social e que recaem sobre a ciência moderna, o que inclui o direito. que se desenvolve. Além disso, contribui e dá maior possibilidade de respeito às diversas lutas populares que resistem opressões e silenciamentos. Os países latino-americanos precisam deixar de se espeIhar em conjuntos de instituições, normativas, ideologias do Norte global e voltarem-se para si mesmos, o que significa buscar outras formas de lidar com seus próprios problemas. Não se pretende, contudo, um radicalismo do pensamento descolonial. Não se trata de rechaçar tudo que advenha do Norte Global. Sugere-se, apenas, que haja uma reflexão sobre os limites e alcances do direito e o mesmo deve ser aplicado ao pensamento descolonial.

As reflexões propostas se justificam ante a necessidade do papel do jurista e da pesquisa científica. Isso porque as pesquisas jurídicas não podem ignorar as dinâmicas de poder contidas na construção social e que recaem sobre a ciência moderna, o que inclui o direito. $O$ jurista, à medida que der conta criticamente do paradigma do Direito moderno, poderá ser uma das grandes forças na luta para a sua reformulação, pautando-se em uma prática contínua e que não se pode esgotar. Sendo assim, no que tange ao ofício do jurista (crítico), pensamos que ele seja, sobretudo, o denunciador de opressões legitimadas pelo próprio direito.

Para tanto, o primeiro tópico considera a historicidade crítica como elemento desmistificador, demonstrando o direito como fenômeno social e não como uma ciência pura e mitificada. Nessa trilha, realizou-se um resgate de aportes teóricos e reflexões com base no campo sócio-histórico crítico, dirigidas para a universalidade a eles apregoada, em fato, se trata de uma jogada política para globalização de um pensamento local, o do Ocidente. Portanto, o estudo busca explorar o Direito, por meio de suas características social-político-geográficas e explicar sua incompatibilidade com a realidade do pensamento do Sul global.

No segundo tópico, o pensamento descolonial possibilitou o desvelar epistemológico das realidades silenciadas, enfrentando criticamente o paradigma moderno/colonial e as relações de colonialidade formadas nos movimentos hegemônicos mundiais. Com base nas epistemologias do Sul é possível oferecer uma nova compreensão do Direito ${ }^{1}$. Assim, a urgência de se interrogar sobre um Direito pautado nas

${ }^{1}$ SANTOS, 1997; 2000; 2004; 2010 
epistemologias do Sul advém da inquietação quanto às promessas não cumpridas da modernidade, que convoca o Direito a acolhê-las como seu fundamento. Pensar num Direito Latino-Americano fundado nas epistemologias do Sul é pensar um Direito que tenha um rosto próprio, que se manifeste não simplesmente mediante a adoção de fórmulas Ocidentais, mas por intermédio de uma linguagem apropriada que interpele a quem quer que seja, a fim de que se sinta responsável por tudo e por todos, antes mesmo de qualquer liberdade ${ }^{2}$.

No terceiro tópico, indaga-se: Por que buscar um direito descolonial? Seria o Novo Constitucioalismo Latino-Americano descolonial? A busca por respostas evidenciaram os dilemas da modernidade e a necessidade de reavaliarmos elementos que subsidiam a consolidação do projeto de vida moderno.

Objetivando colmatar a investigação científica ora proposta, a partir de uma pesquisa bibliográfica, a pesquisa entrecruza diversos vieses epistemológicos donde emerge seu caráter interdisciplinar, propiciando complementações teóricas e diálogos entre saberes.

\section{PODE O DIREITO SER DESCOLONIAL?}

É sabido que, não raramente, o direito legitima práticas opressoras. Existe um avanço das lutas sociais ao longo da história, por outro lado, o colonialismo adquire novas roupagens que atuam cegamente em benefício de interesses econômicos e culturais. Diante deste emblema, faz-se necessário indagar: existe um direito latino-americano ou somos replicadores de epistemologias e fórmulas ocidentais? Um direito descolonial é possível ? ${ }^{3}$

Para orientar esse desvelar do Sul, teorias críticas latino-americanas muito contribuem ao pensamento descolonial, pois permitem uma reflexão dos mais variados temas e formas de conhecimento,

\footnotetext{
2 DUSSEL, 1977; WOLKMER, 2001; ACOSTA, 2016.

${ }^{3}$ A teologia da libertação (DUSSEL, 2007; BRAGATO; CASTILHO, 2014) e a teoria da dependência (DOS SANTOS, 2015) relacionam-se com as questões por de trás dessas indagações. São exemplos de pessoas que buscaram o desvelar do indivíduo e do mundo latino-americano: Gustavo Guterres, Camilo Torres, Arturo Roig, Horacio Cerutti, Enrique Dussel, Milton Santos, Darcy Ribeiro, Paulo Freire, Florestan Fernandes, Orlando Fals Borda, Celso Furtado, José Julián Martí Pérez, Mercedes Sosa, Augusto Boal, Glauber Rocha, Mario Benedetti, Ernesto Sabato, Gabriel García Márquez, Jorge Amado, Pablo Neruda, Rubén Darío, Oscar Correa. Esses pensadores comumente são criticados por buscarem uma filosofia periférica não universal, diferentemente da filosofia local grega alemã, europeia que, por outro lado, majoritariamente é tida como uma fórmula superior e universal às sociedades.
} 


\section{O pensamento descolonial mostra-se capaz de dar autonomia ao indivíduo para que compreenda os processos histórico-sociais em que se desenvolve a América Latina, bem como o colonialismo inerente ao continente e a si próprio, enquanto ser latino- americano e, portanto, produto e reprodutor de colonizações.}

demonstrando a possibilidade e existência de pressupostos filosóficos, políticos e metodológicos contra-hegemônicos.

As principais referências teóricas desse pensamento advém do Projeto M\&C (Modernidade e Colonialidade), composto por estudos de Aníbal Quijano, Enrique Dussel, Catherine Walsh, Boaventura de Sousa Santos, Freya Schiwy, José Saldívar, Nelson Maldonado-Torres, Fernando Coronil, Javier Sanjinés, Margarida Cervantes de Salazar, Libia Grueso, Marcelo Fernádez Osco, Edgardo Lander, Arturo Escobar.

O pensamento descolonial mostra-se capaz de dar autonomia ao indivíduo para que compreenda os processos histórico-sociais em que se desenvolve a América Latina, bem como o colonialismo inerente ao continente e a si próprio, enquanto ser latino-americano e, portanto, produto e reprodutor de colonizações. Além disso, contribui e dá maior possibilidade de respeito às diversas lutas populares que resistem a um histórico processo de opressões e silenciamentos ${ }^{4}$. Isso porque o direito, quando atrelado às memórias sociais, é capaz de desenvolver um sentimento de identidade, de pertença, de alteridade e de busca por transformações, principalmente aos que se encontram excluídos e invisibilizados. Consequentemente, mostra-se possível um ser latino-americano apto a se descolonizar e a descolonizar ao seu redor.

Descolonizar-se trata de uma postura de questionamento e de desconfiança àquilo que se é posto, seja uma lei, um ensino, um livro, uma fala. Trata-se de buscar identificar o ideológico por detrás dos interesses. Isso abarca o desvelar do conhecimento, da cultura e da economia que nos são impostos a partir de uma lógica monocultural (a do Ocidente) que se legitima com fundamentos absolutos ou transcendentais orientados a desqualificar o diferente e a desvalorizar as demais formas de vida e de identidades.

\section{PODEM O CONSTITUCIONALISMO, OS DIREITOS HUMANOS E A DIGNIDADE HUMANA SEREM DESCOLONIAIS?}

Ao indagar sobre o potencial descolonizador do direito, é necessário indagar sobre o constitucionalismo. Mais que isso, mostra-se primordial uma reflexão acerca das raízes epistemológicas do direito.

${ }^{4}$ FLORES, 2009. 
Durante cinco séculos, desde a expansão marítima e comercial, a Europa, particularmente, vem ensinando ao mundo acerca da história da civilização, direitos humanos, constitucionalismo, natureza, democracia, cidadania, organização e limites do Estado ${ }^{5}$. A crença na necessidade de doutrinar o mundo, ditar suas normas e saberes, bem como em estabelecer o que vem a ser o progresso, são, basicamente, de caráter imperialista e colonialista. Estes ideais andam a par de violências que fazem parte da história europeia e a América do Norte utiliza da mesma estratégia. São muitas as faces da opressão e dominação e várias delas foram negligenciadas pelos estudos críticos do direito. De acordo com Santos:

O direito natural racionalista dos séculos XVII e XVIII, também faz parte deste processo, na medida em que serviu para legitimar, quer o despotismo iluminado quer as ideias liberais e democráticas que conduziram à Revolução Francesa, partindo, portanto, do modelo de racionalidade descrita. Portanto, há contrariedade entre os direitos naturais tidos como universais como forma de emancipação social. Dessa forma, tanto a virada Kantiana, como o raciocínio iluminista, o constitucionalismo liberal e, posteriormente, a internacionalização dos direitos humanos fazem parte da mesma faceta colonizadora. $\mathrm{O}$ aprimoramento dos direitos humanos por meio do Welfare-State serviu como forma de gestão capitalista, pois ao Estado providência coube a gestão das desigualdades e à teoria dos direitos humanos a gestão da exclusão ${ }^{6}$.

A história do constitucionalismo demonstra uma preocupação em demasia para com a forma do direito, em detrimento do conteúdo em si. O positivismo separou direito e moral. Com a Segunda Guerra Mundial, houve uma reaproximação entre estes, por meio da ideologia pós-positivista, que prima pela proteção de valores contidos em direitos fundamentais de natureza eurocêntrica que acabam por se auto violarem quando diante do pluralismo sociocultural. ${ }^{7}$

\footnotetext{
${ }^{5}$ Para maior aprofundamento nessas questões, ver os estudos de Parola (2017) e Bello (2018).

${ }^{6}$ SANTOS, 2000, p. 126.

${ }^{7}$ Lenio Streck (2012) parte da premissa de que o neo-constitucionalismo emergiu a partir da Segunda Guerra Mundial, preferindo denominá-lo de "Constitucionalismo Contemporâneo". Existem três marcos do processo evolutivo do direito constitucional contemporâneo: histórico, filosófico e teórico. O marco histórico corresponde à Lei Fundamental de Bonn (Constituição Alemã, 1949), efetivada anteriormente aos direitos fundamentais contidos na Constituição Italiana, de 1948, por meio da instauração do Tribunal Constitucional Federal, em 1951, ocorrendo a reconstitucionalização no Brasil em 1988; o filosófico diz respeito ao ideal pós-positivista. Quanto ao teórico, relacionase à matéria de aplicação do direito constitucional, e demonstra três relevantes características: "O reconhecimento da força normativa da Constituição, a expansão da Jurisdição Constitucional e o desenvolvimento de uma nova dogmática de interpretação constitucional" (BARROSO, 2005, p. 6).
} 
Enquanto teóricos debruçam-se acerca da distinção entre princípios e regras, não veem o contexto abissal ${ }^{8}$ em que estas se inserem. Isso porque as razões do colapso do positivismo são similares as do pós-positivismo, pois ambos permitem barbáries em nome da lei, por serem incapazes de compatibilizar o direito positivado à realidade social. Assim, a constituição configura mais um documento político do que propriamente um instrumento jurídico emancipador.

Como cerne dessa problemática encontra-se o ocidentalismo que se supõe fonte epistêmica de conhecimento, como que superior às demais, desprezando saberes do mundo e outras espiritualidades, taxando-as de inferiores ante à imposta razão científica do homem ocidental. Isso resulta na racionalização da ciência do direito a uma visão universal de valores, modelos e definições que refletem a própria existência do europeu. É justamente na percepção do Outro enquanto "primitivo", "bárbaro", "arcaico", "tradicional", "simples" ou "selvagem" que o Ocidente vem produzindo a imagem e a reafirmação de si mesmo. O conceito colonial ocidental de modernidade colocou a América Latina em lugar periférico, rotulando o continente em "subdesenvolvido" ou "em desenvolvimento", evidenciando uma "ontologia da totalidade".

Com relação aos direitos humanos e a dignidade humana, se mostram, simultaneamente, desde sua origem, uma política reguladora e uma política emancipadora. ${ }^{9}$ A concepção de que os direitos humanos são universais porque pertencem "a todos os seres humanos enquanto seres humanos, ou seja, porque, independentemente do seu reconhecimento explícito, eles são inerentes à natureza humana"10, significa que os seres não detêm direitos, mas porque são humanos possuem características universais inerentes à natureza dos humanos. Explicando: o ser humano ${ }^{11}$, sob essa ótica, é entendido

\footnotetext{
${ }^{8}$ Adjetivo muito utilizado por Santos (2000) para descrever o pensamento moderno ocidental. De acordo com ele, a epistemologia ocidental baseia-se em um sistema de distinções entre visível e invisível que dividem a realidade social em dois universos distintos: "deste lado da linha" e "do outro lado da linha". A distinção ocorre na medida em que "o outro lado da linha" desaparece como realidade, se produzindo apenas como ausência, invisibilidade, inexistência. A característica principal desse pensamento é a impossibilidade da co-presença dos dois lados da linha. As representações mais cabais são o conhecimento e o direito modernos. Eles formam as duas principais linhas abissais globais dos tempos modernos e são interdependentes.

${ }^{9}$ SANTOS, 1997.

${ }^{10}$ SANTOS, 2010, p. 443.

11 Importante mencionar que os direitos são comumente mencionados direcionando-os ao "indivíduo" ou "homem", como uma suposta "generalização", sendo que na verdade
} 
como um vazio, um eco, um não-ser. Foi necessário esvaziá-lo e entendê-lo com direitos universais para compreender sua essência. Assim, universalizou-se a essência do humano, suas características identitárias e epistemológicas, resultando, no final das contas, na imagem do Norte global.

Portanto, a universalidade da compreensão sobre o humano é baseada em direitos que remetem a uma marca ocidental, mais ainda, a uma marca ocidental liberal, a exemplo da Declaração Universal de 1948, elaborada sem a participação da maioria dos povos do mundo. Aqueles que não se identificam ou não se encaixem nessa concepção de direitos humanos não são humanos.

O que caracteriza o humano não é sua estrutura, mas suas diferenças oriundas de características sócioculturais. Sem ele é um objeto, um vazio. Dessa forma, portanto, não existe "dignidade humana", nem "direitos humanos" universais. Mas dignidades e concepções de direitos daquilo que cada cultura entende por universal. Isso significa que toda cultura e saber são incompletos e diferentes, evidenciando a premissa de diálogo e tradução. É necessário uma hermenêutica intercultural de suspeição contra supostos universalismos ou totalidades.

O método utilizado para a tradução intercultural sugerido por Panikkar (2004) é a hermenêutica diatópica que, de acordo com Santos (2000), consiste em na explicação de uma necessidade, uma aspiração ou uma prática numa dada cultura, de forma que se torne compreensível e inteligível para outra cultura. Portanto, é necessário fazer conhecer as epistemologias do Sul, de forma que não sejam mais vistas e descritas como inferiores às do Norte global. As formas dominantes de sociabilidade podem continuar a reproduzir-se, embora, sem o monopólio sobre as práticas epistemológicas e sociais, pois todos os conhecimentos fazem parte de uma amálgama, uma "ecologia de saberes"12

Por meio da hermenêutica diatópica, amplia-se ao máximo a consciência da necessidade mútua, de maneira a favorecer sempre o diálogo com outras epistemologias. Da mesma forma, possibilita mostrar o lado incompleto da cultura ocidental que estabelece dicotomias rígidas ao indivíduo e sociedade, tais como: "cultura científica/cultura

12 SANTOS, 2010, p. 137. 


\section{Mostra-se pertinente analisar constituições que apresentam epistemologias do} Sul como tentativa de emersão de um giro paradigmático como resposta prudente a questões das quais a modernidade não foi apta a lidar, trocando aquele conhecimento científico e conservador por um senso comum, novo e descolonial. literária, conhecimento científico/conhecimento tradicional, homem/ mulher, cultura/natureza"13.

Mostra-se pertinente analisar constituições que apresentam epistemologias do Sul como tentativa de emersão de um giro paradigmático como resposta prudente ${ }^{14}$ a questões das quais a modernidade não foi apta a lidar, trocando aquele conhecimento científico e conservador por um senso comum, novo e descolonial.

A redefinição do direito pautado em concepções contra-hegemônicas é capaz de romper com dicotomias, redefinindo, inclusive, a base do constitucionalismo moderno: a dignidade humana ${ }^{15}$. Isso porque a dignidade, essência da proteção dos direitos humanos, é aquilo que cada povo entende por mais essencial, o que justifica a necessária redefinição dos pressupostos básicos do jusnaturalismo racionalista-contratualista, face sua íntima relação com o colonialismo.

Como consequência, não há mais definições dos núcleos dos direitos, pois são diversas as concepções culturais, de forma a entrelaçá-las, bem como as possíveis acepções do que se entende por Bem-viver ou vida digna, configurando um sistema de alternativas.

Para alcançar uma transformação de caráter descolonial, como explicado alhures, faz-se necessário um diálogo intercultural sobre a dignidade humana e direitos humanos. Para alcançar esse objetivo, é preciso: 1) superar o debate sobre universalismo e relativismo cultural, sendo que "Contra o relativismo, há que desenvolver critérios políticos para distinguir política progressista de política conservadora, capacitação de desarme, emancipação de regulação." ${ }^{\prime 16}$; 2) transformação cosmopolita dos direitos humanos, que implica na compreensão de que todas as culturas possuem concepções de dignidade humana, mas nem todas elas a concebem em termos de direitos humanos, mesmo que tenham preocupações ou aspirações semelhantes ou mutuamente inteligíveis; 3) compreensão de que todas as culturas são incompletas e problemáticas no que entendem por dignidade humana; 4) compreensão de que todas as culturas

\footnotetext{
${ }^{13}$ SANTOS, 2000, p. 739.

${ }^{14}$ A transição epistemológica que ocorre entre o paradigma dominante da ciência moderna e o paradigma emergente é designado por Santos de "Conhecimento prudente para uma vida decente" (SANTOS, 2004).

15 FLORES, 2009.

${ }^{16}$ SANTOS, 1997, p. 21.
} 
possuem versões diferentes de dignidade humana, sejam elas mais amplas ou não com relação às outras, havendo certa reciprocidade ou não; 5) compreensão de que todas as culturas tendem a distribuir as pessoas e os grupos sociais entre dois princípios competitivos de pertença hierárquica: o princípio da igualdade e o princípio da diferença. ${ }^{17}$

\section{O NOVO CONSTITUCIONALISMO LATINO-AMERICANO: UM PASSO RUMO A UM DIREITO DESCOLONIAL?}

O Novo
Constitucionalismo
Latino-Americano
demonstra a
renovação de
diversos setores
políticos e das
dinâmicas sociais
da América Latina,
ao colocar em
questionamento
os sistemas e
conhecimentos
hegemônicos. Isso
porque aponta a
necessidade de
se repensar uma
teoria crítica desde
el Sul e de viés
periférico.

O Novo

Constitucionalismo

O Novo Constitucionalismo Latino-Americano demonstra a renovação de diversos setores políticos e das dinâmicas sociais da América Latina, ao colocar em questionamento os sistemas e conhecimentos hegemônicos. Isso porque aponta a necessidade de se repensar uma teoria crítica desde el Sul e de viés periférico. Refletem anseios de sujeitos emergentes, subalternos, minorias, indígenas, afrodescendentes, na tentativa de mudar o status quo, referido alhures, e não mais silenciar as epistemologias do Sul. Sendo assim, o Novo Constitucionalismo Latino-Americano baseia-se na busca por rompimento com categorias pós-coloniais ${ }^{18}$ e implementa ações de caráter descolonial. ${ }^{19}$

O Novo Constitucionalismo Latino-Americano pode ser entendido como um processo de transição. Isso porque ainda não efetivou rompimentos epistemológicos consubstancias, necessários à realidade sócio-histórica do Sul. No entanto, ainda assim, configura um projeto com o diferencial de ser pautado na praxe material, ao partir da realidade latino-americana. No plano epistemológico, traz novas concepções de mundo, ao consagrar cosmologias indígenas nas constituições, a exemplo a da Bolívia e do Equador, que objetivam proteção à Pachamama. Pachamama é a deidade máxima dos Andes, protetora da natureza, cujo nome Quéchua significa Mãe Terra.

\footnotetext{
17 SANTOS, 1997.

${ }^{18}$ O pós-colonialismo é um período posterior à colonização, com a declaração de independência dos países, mas ainda marcado por forte dependência entre colonizadores e ex-colônias.

${ }^{19}$ Descolonialismo trata-se de um pensamento crítico baseado na noção de ruptura de todas as formas de colonialismo existentes no pós-colonialismo, a exemplo da teoria crítica clássica eurocêntrica. Walter Mignolo (2009) e Catherine Walsh (2008) adotam a terminologia "decolonialismo". Enrique Dussel, Anibal Quijano, Castro Gomes são exemplos de autores críticos que buscam uma perspectiva latino-americana. A busca por essa teoria crítica baseada na identidade latino-americana resulta na averiguação de características marcantes de nosso continente: alteridade, pluralidade e interculturalidade.
} 


As epistemologias
indígenas,
consagradas
por essas
constituições,
possibilitam
uma revisão
crítica de dogmas
constitucionais
ocidentais tidos
como intangíveis,
mostrando uma
alternativa ao
desenvolvimento
econômico,
político e social
dominantes

As epistemologias indigenas, por essas constituições, possibilitam uma revisão crítica de dogmas constitucionais ocidentais tidos como intangiveis, mostrando uma alternativa ao econômico, dominantes
Esse ser espiritual exige respeito e cooperação dos demais seres para com ela. Sua consagração pela Constituição do Equador objetiva respeito aos ciclos naturais ecológicos, o que implica na rejeição da teoria utilitarista dos recursos naturais sobre a qual se alicerça o capitalismo. ${ }^{20}$

As constituições da Bolívia e do Equador inserem-se no marco do Novo Constitucionalismo Latino-Americano, denominado por Fajardo (2011) de constitucionalismo plurinacional. Um evidente giro paradigmático, com relação à proposta desse ciclo constitucional, decorre da disposição de seus textos que optam por referir-se sempre à mulher e ao homem a generalizá-los, por meio de palavras como "indivíduo" ou "homem" (sempre no singular e no masculino).

As epistemologias indígenas, consagradas por essas constituições, possibilitam uma revisão crítica de dogmas constitucionais ocidentais tidos como intangíveis, mostrando uma alternativa ao desenvolvimento econômico, político e social dominantes. É por isso que as atuais constituições da Bolívia (2007) e do Equador (2008) rompem com modelos ocidentais ao incorporar saberes não liberais seus textos, tais como o Sumak Kawsay e o Suma Qamaña ${ }^{21}$ que objetivam proteção à Pachamama. Assim, inserem-se no paradigma do Novo Constitucionalismo Latino-Americano por proporcionarem um giro paradigmático, ao afastar o modelo constitucional ocidental antropocêntrico para vigorar um biocêntrico de dignidade ${ }^{22}$.

O que se entende por progresso não é aquele trazido propriamente pelo conhecimento do Norte global, que na verdade assinala a crise no desenvolvimento econômico-social-ambiental por possuir caráter

\footnotetext{
${ }^{20}$ ZAFFARONI, 2010.

${ }^{21}$ Sumak Kawsay e Suma Qamaña são valores indígenas que não possuem tradução nas línguas coloniais. O significado mais próximo seria Buen Vivir. No entanto, não possuem conotação a um viver bem utilitarista. Sumak Kawsay foi consagrada pela Constituição equatoriana. Trata-se de uma expressão Quéchua, idioma tradicional dos Andes. Sumak significa o ideal, o belo, o bom, realização, plenitude; Kawsay quer dizer viver, vida digna, harmonia e equilíbrio entre o universo e o ser humano. A postura biocêntrica do Equador, ao reconhecer a Natureza como sujeito de direitos, demonstra uma alternativa ética de aceitar que o meio ambiente possui valor intrínseco, ontológico. (ACOSTA, 2016). O Suma Qamaña é uma expressão similar, mas da etnia boliviana Aimará. Refere-se ao Buen Vivir, relacionada à ideia de olhar o passado, viver o presente, para projetar o futuro como sonho de vida plena. (ZAFFARONI, 2010). A constituição boliviana não possui caráter biocêntrico, pois, embora outorgue ideais não liberais, também abarca a clássica ideia do progresso baseado na apropriação da Natureza. Ainda assim, no processo que quebra paradigmática, são as constituições mais avançadas nesse sentido.

22 Segundo Zaffaroni (2012), o biocentrismo afirma o direito à dignidade de todos os seres vivos, incluindo os não humanos, sendo, portanto, uma alternativa ao modelo normativo antropocêntrico.
} 
puramente liberal. Na concepção do Buen Vivir, avanço civilizacional é aquele que proporciona garantia de vida aos seres humanos e inumanos, bem como às futuras gerações ${ }^{23}$, de forma a alcançar equidade intergeracional a todos os seres vivos. Essa ética se aproxima das propostas da sustentabilidade forte ${ }^{24}$ e da ecologia profunda que reconhecem a interdependência entre homem-natureza ${ }^{25}$. No entanto, diferem-se muito pelo fato da primeira ser fortemente marcada por um viés liberal e a segunda restrita a uma concepção ocidental da Natureza. ${ }^{26}$ Por meio das epistemologias do Sul é possível apreender uma nova perspectiva de vida.

Na concepção do Buen Vivir, avanço civilizacional é aquele que proporciona garantia de vida aos seres humanos e inumanos, bem como às futuras gerações, de forma a alcançar equidade intergeracional a todos os seres vivos. Essa ética se aproxima das propostas da sustentabilidade forte e da ecologia profunda que reconhecem a interdependência entre homemnatureza.
Sendo assim, a positivação do Sumak Kawsay e do Suma Qamaña instauram um novo marco epistemológico constitucional. A inserção de cosmologias indígenas em textos constitucionais faz com que os países ameríndios tendam a atender aos anseios da América Latina. Mecanismos de atuação popular com legitimidade para reforma constitucional boliviana (artigo 411) proporcionam a integração de sociabilidades até então invisibilizadas. Assim, supera-se a lógica da democracia essencialmente representativa de legitimidade participativa que se esgota no ato da eleição de seus representantes; combate os excessos de regulamentação da modernidade, por ins-

\footnotetext{
23 Importante mencionar que a justificativa de proteção à Natureza baseada no direito intergeracional e na sustentabilidade não são suficientemente capazes de garantir-Ihe direitos ou assegurar vida a todos os seres, pois o "montante" natural que se deve deixar às gerações futuras é subjetivo e insuficiente para prever suas necessidades no futuro. Quanto à sustentabilidade, Bosselmann (2015) tece relevante crítica ao princípio, por este ser fortemente marcado por um viés liberal. Além do mais, ambos, direito intergeracional e sustentabilidade, possuem como finalidade à proteção ambiental interesses antropocêntricos.

${ }^{24}$ A sustentabilidade forte trata-se de uma abordagem ecologista de desenvolvimento sustentável e difere-se da sustentabilidade fraca que coloca em paridade de importância a sustentabilidade ambiental, a justiça social e a prosperidade econômica.
}

25 BOSSELMANN, 2015.

${ }^{26}$ Não é o objetivo do presente estudo o aprofundamento dessas questões, limitando-se a mencionar que muitas das tentativas de fundamentação dos direitos da Natureza encontram-se dentro do paradigma da modernidade (kantiano, antropocêntrico, liberal ou ocidental). Noções e termos, contidos nessas tentativas, estão muito ligados a uma concepção ocidental do direito e da Natureza, não possibilitando distintos significados, como o fazem as epistemologias do Sul. O mesmo pode-se dizer com relação aos "bens comuns" que, de acordo com Svampa (2016, p. 140-141), "a referência em torno dos bens comuns aparece intimamente associada à de território. Assim, não se trata exclusivamente de uma disputa em torno dos 'recursos naturais', mas de uma disputa pela construção de um determinado 'tipo de territorialidade' baseado na proteção do 'comum' (patrimônio natural, social e cultural)". Portanto, "bem comum", ainda que se mostre um instrumento eficaz ao direito à autonomia e ao território de povos tradicionais, está distante da proteção da natureza como um fim em si mesma. A própria noção de "injustiça ambiental" (FENSTERSEIFER, 2010) não remete à injustiça à Natureza em si, pois relaciona-se à degradação e poluição ambiental que afeta, principalmente, indivíduos e grupos sociais de baixo poder econômico. 
tituir outros parâmetros do que se entende por legal/ilegal; afasta as tendências hegemônicas da ordem ocidental global. Consequentemente, há uma quebra do padrão de juridicidade que reproduz o monismo jurídico, ao negar que o "Estado seja o centro único do poder político e a fonte exclusiva de toda produção do Direito". ${ }^{27}$ Nesse mesmo percurso, Tapia (2007) entende que o Estado assume uma postura correspondente à realidade social e com a insurgência das demandas da população, configurando uma nova ordem jurídica amplamente plural.

Dessa forma, ocorre a necessária redefinição não somente das funções do direito, como também das concepções hegemônicas de direitos fundamentais, rompendo com a antiga dicotomia entre estes e os direitos humanos advindos do Ocidente, redefinindo, inclusive, a base do constitucionalismo moderno: a dignidade humana ${ }^{28}$. Isso porque a dignidade é aquilo que cada povo entende por mais essencial, o que justifica a necessária redefinição dos pressupostos básicos do jusnaturalismo racionalista-contratualista, face sua íntima relação com o colonialismo. Como consequência, não há mais definições dos núcleos dos direitos, pois são diversas as concepções culturais, de forma a entrelaçá-las, bem como as possíveis acepções do que se entende por Bem-viver, configurando um sistema de alternativas.

\section{CONCLUSÃO}

As constituições da Bolívia e do Equador permitem reflexões, não só porque representam um marco instaurado pelo povo, mas também porque aponta questões que as sociedades são capazes de avançar. O fato de projeto inovador advir de setores marginalizados, fez com que, a princípio, fosse visto como separatista, divisionista ou mesmo invisibilizado. Foi a pressão popular que conseguiu que se instituísse a refundação dos Estados, ou seja, a transformação dos Estados coloniais, capitalistas, patriarcais e monoculturais em Estados plurinacionais e interculturais como transição para uma nova forma de organização social, política e econômica. O projeto era consciente de que alternativas poderiam ser encontradas em epistemologias marginalizadas, excluídas e invisibilizadas, em especial, as dos

\footnotetext{
27 WOLKMER, 2001, p. XV.

28 FLORES, 2009.
} 
movimentos indígenas. Por isso, essa proposta vai muito além de uma refundação do Estado, trata-se de um projeto que objetiva superar o colonialismo, o neocolonialismo e a noção de desenvolvimentismo a nível local, regional e internacional.

Houve articulação de movimentos indígenas com outros segmentos sociais pressionaram para que fosse viabilizada a proposta de Estado plurinacional e intercultural. Uma vez aprovadas as constituições, foram realizados diversos estudos em diferentes perspectivas, pois as artimanhas coloniais continuam se repetindo. Isso decorre do fato de serem ignoradas tanto as visões como as concepções das epistemologias do Sul propostas e, ainda, persistir o olhar epistemológico ocidental sobre a natureza, a vida, o ser. Nesse sentido, essas constituições são a parte formal do que preparará a Bolívia e o Equador para o processo de transição Estatal, compreendendo-as, portanto, como constituições de experimentação ou de transição. Portanto, o caminho para a efetivação desse projeto social é longo, mas já está sendo construído.

As constituições da Bolívia e do Equador são uma verdadeira tentativa de responder a essas questões e solucionar o dilema jurídico-social da modernidade: a herança colonial e imperial. Ainda que a América Latina utilize de um instrumento de origem ocidental para descolonização, a constituição, é possível proporcionar rupturas paradigmáticas. Isso porque o Novo Constitucionalismo LatinoAmericano, no qual se inserem essas constituições, não advém das elites políticas e de dogmas contidos em doutrinas de professores de direito. Ao contrário, são modelos originados das lutas sociais de povos subalternizados e com projetos que refletem epistemologias das camadas sociais oprimidas, vulneráveis, marginalizadas, invisibilizadas. Portanto, o constitucionalismo pode ser transformador do status quo, desde que os povos se organizem politicamente para que o seja. A constituição por si e entregue aos juízes e às autoridades estatais não possuem tal potencial. A mobilização jurídica só será emancipatória se estiver a par da realidade social. 


\section{REFERÊNCIAS}

ACOSTA, Alberto. O bem viver: uma oportunidade para imaginar outros mundos. Tradução Tadeu Breda. São Paulo: Autonomia Literária. Elefante: 2016.

BARROSO, Luis Roberto. Neoconstitucionalismo e constitucionalização do direito: o triunfo tardio do Direito Constitucional no Brasil. Net, Rio de Janeiro, nov. 2005. Jus Navigandi. Disponível em: http://jus.com.br/artigos/7547/ neoconstitucionalismo-e-constitucionalizacao-do-direito. Acesso em: 10 jan. 2017.

BELLO, Enzo. A cidadania no constitucionalismo latino-americano. 2. ed. Rio de Janeiro: Lumen Juris, 2018.

BITTAR, Eduardo C. B. Metodologia da pesquisa jurídica: teoria e prática da monografia para os cursos de direito. 11. ed. São Paulo: Saraiva, 2013.

BOSSELMANN, Klaus. O princípio da sustentabilidade: transformando direito e governança. Tradução Phillip Gil França. São Paulo: Revista dos Tribunais, 2015.

BRAGATO, Fernanda Frizzo; CASTILHO, Natalia Martinuzzi. A importância do pós-colonialismo e dos estudos descoloniais na análise do Novo Constitucionalismo Latino-Americano. In: VAL, Eduardo Manuel; BELLO, Enzo (Orgs.). O pensamento pós e descolonial no Novo Constitucionalismo Latino-Americano [recurso eletrônico]. Caxias do Sul, Educs, 2014, pp. 11-25.

DALMAU, Rubén Martinez; SILVA JÚNIOR, Gladstone Leonel da. O novo constitucionalismo latino-americano e as possibilidades da constituinte no Brasil. In: RIBAS, Luiz Otávio (Org.). Constituinte exclusiva: um outro sistema político é possível. p. 22-23. Disponível em: < http://www.plebiscitoconstituinte.org.br/sites/ default/files/material/Livro\%20Juridico\%20Constituinte\%20 Exclusiva\%202014.pdf >. Acesso em: 08 set. 2018.

DOS SANTOS, Theotonio. Teoria da dependência: balanço e perspectivas. Obras escolhidas. V.1. Florianópolis: Insular. Reedição ampliada e atualizada, 2015.

DUSSEL, Enrique. Filosofia da libertação na América latina. Tradução Luiz João Gaio. 2. ed. São Paulo: Loyola, UNIMEP, 1977.

FENSTERSEIFER, Tiago. A responsabilidade do estado pelos danos causados às pessoas atingidas pelos desastres ambientais associados às mudanças climáticas: uma análise à luz dos deveres de proteção ambiental do estado e da proibição de insuficiência na tutela do direito fundamental ao ambiente. In: CONGRESSO 
INTERNACIONAL DE DIREITO AMBIENTAL 14. São Paulo: Imprensa Oficial do Estado de São Paulo, 2010. pp. 389-420.

FLORES, Joaquin H. A (re)invenção dos direitos humanos. Tradução Carlos R. D. Garcia; Antonio H. G. Suxberger; Jefferson A. Dias. Florianópolis: Fundação Boiteux, 2009.

MIGNOLO, Walter. La idea de América Latina (la derecha, la izquierda y la opcion decolonial). Crítica y Emancipación, (2): 251276, primer semestre, 2009.

PAROLA, Giulia. O modelo teórico da democracia ambiental: uma introdução à obra. In: AVZARADEL; Pedro C. S.; PAROLA, Giulia; VAL, Eduardo Manuel (Orgs). Democracia ambiental na América Latina: Uma abordagem comparada. Rio de Janeiro: Multifoco, 2017, pp. 81-110.

PANIKKAR, Raimon. Seria a concepção de direitos humanos uma noção ocidental? In: BALDI, César Augusto (Org). Direitos humanos na sociedade cosmopolita. Tradução: Roberto Cataldo Costa. Rio de Janeiro: Renovar, 2004. pp. 205-238.

SANTOS, Boaventura de Sousa. A crítica da razão indolente: contra o desperdício da experiência. São Paulo: Cortez, 2000.

SANTOS, Boaventura de Sousa. A gramática do tempo: para uma nova cultura política. 3. ed. São Paulo: Cortez, 2010.

SANTOS, Boaventura de Sousa. (Org). Conhecimento prudente para uma vida decente: um discurso sobre as ciências revisitado. São Paulo: Cortez, 2004.

SANTOS, Boaventura de Sousa. Por uma concepção multicultural de direitos humanos. In: Revista crítica de ciências sociais. no 48, junho 1997, pp. 11-32. Disponível em: < http://www. boaventuradesousasantos.pt/media/pdfs/Concepcao_ multicultural_direitos_humanos_RCCS48.PDF >. Acesso em: 1 set. 2017.

STRECK, Lenio Luiz. Neoconstitucionalismo, positivismo e pós-positivismo. In: Garantismo, hermenêutica e (neo) constitucionalismo: um debate com Luigi Ferrajoli. FERRAJOLI, Luigi; STRECK, Lenio Luiz; TRINDADE, André Karam (Orgs.). Porto Alegre: Livraria do Advogado, 2012.

SVAMPA, Maristella. Extrativismo neodesenvolvimentista e movimentos sociais: um giro ecoterritorial rumo a novas alternativas? In: DILGER, Gerhard; LANG, Miriam; PEREIRA FILHO, Jorge. (Orgs.). Descolonizar o imaginário: debates sobre pósextrativismo e alternativas ao desenvolvimento. Tradução: Igor Ojeda. São Paulo: Elefante, Autonomia Literária e Fundação Rosa Luxemburgo, 2016. pp. 140-173. 
TAPIA, Luis. Una reflexión sobre la idea de Estado Plurinacional. Buenos Aires. CLACSO, 2007.

WALSH, Catherine. Interculturalidad, plurinacionalidad y decolonialidad: las insurgências político-epistémicas de refundar el Estado. In: Tabula rasa. no 9, 2008, p. 131-152. Disponível em: <http://www.revistatabularasa.org/numero-9/08walsh.pdf>. Acesso em: 23 ago 2017.

WOLKMER, Antonio Carlos. Pluralismo Jurídico: fundamentos de uma nova cultura no Direito. 4a ed. São Paulo: Alfa Omega, 2001.

YRIGOYEN FAJARDO, Raquel Zonia. El horizonte del constitucionalismo pluralista: del multiculturalismo a la descolonización. In: GARAVITO, César Roberto (Comp.). El derecho en América Latina: un mapa para el pensamiento jurídico del siglo XXI. Buenos Aires: Siglo Veintiuno, 2011, pp. 139-184.

ZAFFARONI, Eugênio Raúl. La natureza como persona: pachamama y gaia. In: VARGAS, Chivi; MOISES, Idón (Coords.) Bolivia - nueva constitucion política del Estado: Conceptos elementales para sudesarrollo normativo, La Paz, 2010.

ZAFFARONI, Eugênio Raúl. La pachamama y el humano. Buenos Aires: Ediciones Madres de Plaza de Mayo, 2012. 